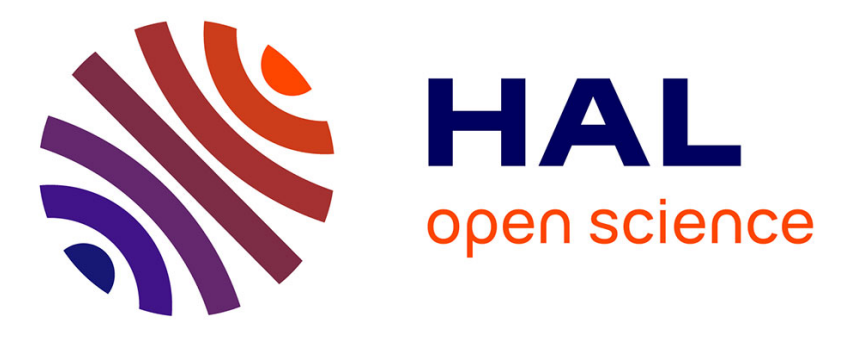

\title{
Carbon nanotube-metal-oxide nanocomposites: microstructure, electrical conductivity and mechanical properties
}

Emmanuel Flahaut, Alain Peigney, Christophe Laurent, Ch. Marlière, Françoise Chastel, Abel Rousset

\section{To cite this version:}

Emmanuel Flahaut, Alain Peigney, Christophe Laurent, Ch. Marlière, Françoise Chastel, et al.. Carbon nanotube-metal-oxide nanocomposites: microstructure, electrical conductivity and mechanical properties. Acta Materialia, 2000, vol. 48, pp. 3803-3812. 10.1016/S1359-6454(00)00147-6 . hal00938352

\section{HAL Id: hal-00938352 \\ https://hal.science/hal-00938352}

Submitted on 29 Jan 2014

HAL is a multi-disciplinary open access archive for the deposit and dissemination of scientific research documents, whether they are published or not. The documents may come from teaching and research institutions in France or abroad, or from public or private research centers.
L'archive ouverte pluridisciplinaire HAL, est destinée au dépôt et à la diffusion de documents scientifiques de niveau recherche, publiés ou non, émanant des établissements d'enseignement et de recherche français ou étrangers, des laboratoires publics ou privés. 


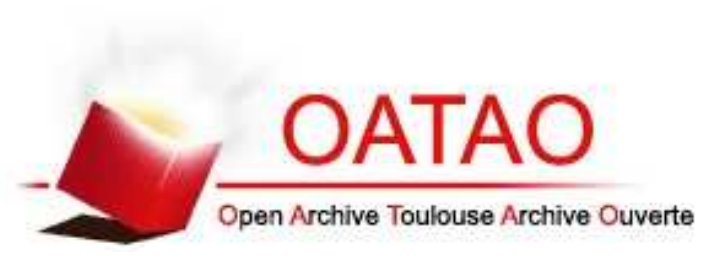

\section{Open Archive TOULOUSE Archive Ouverte (OATAO)}

OATAO is an open access repository that collects the work of Toulouse researchers and makes it freely available over the web where possible.

This is an author-deposited version published in : http://oatao.univ-toulouse.fr/ Eprints ID : 10686

To link to this article : DOI:10.1016/S1359-6454(00)00147-6 URL : http://dx.doi.org/10.1016/S1359-6454(00)00147-6

\section{To cite this version :}

Flahaut, Emmanuel and Peigney, Alain and Laurent, Christophe and Marlière, Ch. and Chastel, Françoise and Rousset, Abel Carbon nanotube-metal-oxide nanocomposites: microstructure, electrical conductivity and mechanical properties. (2000) Acta Materialia, vol. 48 ( $\left.\mathrm{n}^{\circ} 14\right)$. pp. 3803-3812. ISSN 1359-6454

Any correspondance concerning this service should be sent to the repository administrator: staff-oatao@ listes-diff.inp-toulouse.fr 


\title{
CARBON NANOTUBE-METAL-OXIDE NANOCOMPOSITES: MICROSTRUCTURE, ELECTRICAL CONDUCTIVITY AND MECHANICAL PROPERTIES
}

\author{
E. FLAHAUT ${ }^{1}$, A. PEIGNEY ${ }^{1} \dagger^{*}$, Ch. LAURENT ${ }^{1}$, Ch. MARLIÈRE ${ }^{2}$, F. CHASTEL $^{1}$ and \\ A. ROUSSET ${ }^{1}$
}

${ }^{1}$ CIRIMAT, UMR CNRS 5085/ LCMI, Centre Inter-universitaire de Recherche et d'Ingénierie des Matériaux, Université Paul-Sabatier, F 31062 Toulouse, cedex 4, France, ${ }^{2}$ Laboratoire des Verres, UMR CNRS 5587, Université Montpellier 2, C.C. 69, place Eugène Bataillon, F 34095 Montpellier, cedex 5, France

\begin{abstract}
Carbon nanotube-metal-oxide composites (metal=Fe, Co or Fe/Co alloy; oxide $=\mathrm{Al}_{2} \mathrm{O}_{3}, \mathrm{MgO}$ or $\mathrm{MgAl}_{2} \mathrm{O}_{4}$ ) have been prepared by hot-pressing the corresponding composite powders, in which the carbon nanotubes, mostly single or double-walled, are very homogeneously dispersed between the metal-oxide grains. For the sake of comparison, ceramic and metal-oxide nanocomposites have also been prepared. The microstructure of the specimens has been studied and discussed in relation to the nature of the matrix, the electrical conductivity, the fracture strength and the fracture toughness. The carbon nanotube-metal-oxide composites are electrical conductors owing to the percolation of the carbon nanotubes. (c) 2000 Acta Metallurgica Inc. Published by Elsevier Science Ltd. All rights reserved.
\end{abstract}

\begin{abstract}
Résumé-Des composites nanotube de carbone-métal-oxyde (métal=Fe, $\mathrm{Co}$ ou alliage $\mathrm{Fe} / \mathrm{Co}$; oxyde $=\mathrm{Al}_{2} \mathrm{O}_{3}$, $\mathrm{MgO}$ ou $\mathrm{MgAl}_{2} \mathrm{O}_{4}$ ) ont été préparés par frittage sous charge des poudres composites correspondantes, dans lesquelles les nanotubes de carbone, essentiellement mono- ou bi-feuillets, sont dispersés de façon très homogène entre les grains métal-oxyde. Des céramiques et des nanocomposites métal-oxyde ont aussi été préparés pour permettre des comparaisons. La microstructure des échantillons a été étudiée et discutée en relation avec la nature de la matrice, la conductivité électrique, la résistance à la rupture et la ténacité. Les composites nanotube de carbone-métal-oxyde sont conducteurs électriques grâce à la percolation des nanotubes de carbone.
\end{abstract}

Keywords: Hot pressing; Scanning electron microscopy (SEM); Composites; Electrical properties; Mechanical properties

\section{INTRODUCTION}

Amongst the works actually devoted to the possible applications of carbon nanotubes (CNTs), their incorporation in a polymer [1-12], metal [13, 14], or ceramic [15-18] matrix and the characterization of the microstructure and properties of these dense composite materials are investigated. Indeed, it is proposed that owing to their remarkable mechanical properties [19-21], the CNTs could advantageously substituted for carbon fibers as reinforcing elements in composites. Other important particularities of CNTs are their very high aspect ratio and their metallic or semiconducting character $[22,23]$. Thus, their addition to a polymer matrix leads to a very low elec-

* E-mail address: peigney@iris.ups-tlse.fr (A. Peigney)

† To whom all correspondence should be addressed. Tel.: +33-61-55-62-80; fax: +33-61-55-61-63. trical percolation threshold [3] and allows one to obtain, with only very small amounts of CNTs, an electrical conductivity sufficient to provide an electrostatic discharge [7].

CNT-SiC composites have been prepared by Ma et al. [15], who mixed large multiwall carbon nanotubes (MWNTs: $30-40 \mathrm{~nm}$ in diameter) with $\mathrm{SiC}$ powder and hot-pressed the mixture. These authors reported an improvement of about $10 \%$ over monolithic $\mathrm{SiC}$ both in bending strength and fracture toughness, but the microstructure of the dense materials was not fully investigated. Therefore, the contribution of the CNTs to the mechanical properties was not clearly established in this work. The present authors have reported a novel catalytic route for the in situ formation, in a composite powder based on alumina, of single-wall carbon nanotubes (SWNTs) and thin MWNTs [16, 24]. The microstructure and mechanical properties of dense $\mathrm{CNT}-\mathrm{Fe}-\mathrm{Al}_{2} \mathrm{O}_{3}$ materials pre- 
pared by hot-pressing the nanocomposite powders have been investigated $[17,18]$. In comparison to similar carbon-free nanocomposites, the relative densities are lower, the matrix grains are smaller and the fracture strength and fracture toughness are generally markedly lower. Nevertheless, SEM observations of composite fractures indicated that the CNT bundles, which are very flexible, locally act to dissipate some of the fracture energy. Amongst the reasons which could explain the lack of mechanical reinforcement at the macroscopic scale, we reported the too-low volume fraction of CNTs and the presence of others species, notably large diameter $(>15 \mathrm{~nm}$ ) filamentous carbon that we call nanofibres. It was also pointed out that the influence of the nature of the ceramic matrix in which the CNTs are dispersed was to be investigated.

Working on the powder synthesis, the present authors have greatly enhanced both the quantity of CNTs and the quality of carbon (much less nanofibers) in the $\mathrm{CNT}-\mathrm{Fe}-\mathrm{Al}_{2} \mathrm{O}_{3}$ powders $[25,26]$. Furthermore, novel composite powders, CNT-Fe/Co$\mathrm{MgAl}_{2} \mathrm{O}_{4}$ and CNT-Co-MgO, have been synthesized [27-30]. The aims of this work are to prepare dense $\mathrm{CNT}-\mathrm{Fe}-\mathrm{Al}_{2} \mathrm{O}_{3}$ composites containing higher quantities of CNTs and much less nanofibers than those previously investigated [17, 18] and novel dense $\mathrm{CNT}-\mathrm{Fe} / \mathrm{Co}-\mathrm{MgAl}_{2} \mathrm{O}_{4}$ and $\mathrm{CNT}-\mathrm{Co}-\mathrm{MgO}$ composites. For the sake of comparison, ceramics $\left(\mathrm{MgAl}_{2} \mathrm{O}_{4}\right.$ and $\left.\mathrm{MgO}\right)$ and composites without CNTs $\left(\mathrm{Fe} / \mathrm{Co}-\mathrm{MgAl}_{2} \mathrm{O}_{4}\right.$ and $\left.\mathrm{Co}-\mathrm{MgO}\right)$ are also prepared. The microstructure and mechanical properties of these dense materials are investigated. The electrical conductivity at room temperature is also measured, correlated to the apparent quantity of CNTs and compared with values obtained by other authors for CNTpolymer composites.

\section{EXPERIMENTAL}

The preparation of oxide solid solution and CNTmetal-oxide composite powders was described in previous papers [24-29]. By heating up to $1000^{\circ} \mathrm{C}$ in a $\mathrm{H}_{2}-\mathrm{CH}_{4}$ atmosphere, monophased oxide solid solutions are submitted to a selective reduction which leads to the formation of transition metal particles, a few nanometers in diameter, both inside and at the surface of each grain of the powder. When they reach the required size, the surface metal particles catalyze the in situ formation of SWNTs and thin MWNTs which gather in extensively branched bundles and are extremely well dispersed as a web-like network between the matrix agglomerates (Fig. 1a-f). In addition, some carbon is also found in the form of graphene layers wrapping the metal particles which have not catalyzed the formation of CNTs. Statistical studies on HREM images of individual CNTs have shown than over $80 \%$ have only one or two walls, and that most diameters are smaller than $6 \mathrm{~nm} \mathrm{[26,}$ 30]. Carbon-free metal-oxide powders are similarly prepared by heating up to $1000^{\circ} \mathrm{C}$ in a $\mathrm{H}_{2}$ atmosphere. For the sake of brevity, the powders are labeled CMA1, CMA2 (CNT-Fe- $\left.\mathrm{Al}_{2} \mathrm{O}_{3}\right), \mathrm{B}, \mathrm{MB}$ and $\mathrm{CMB}$ ( $\mathrm{MgO}, \mathrm{Co}-\mathrm{MgO}$ and $\mathrm{CNT}-\mathrm{Co}-\mathrm{MgO}$, respectively) and $\mathrm{D}, \mathrm{MD}$ and $\mathrm{CMD}\left(\mathrm{MgAl}_{2} \mathrm{O}_{4}, \mathrm{Co}-\mathrm{MgAl}_{2} \mathrm{O}_{4}\right.$ and $\mathrm{CNT}-\mathrm{Co}-\mathrm{MgAl}_{2} \mathrm{O}_{4}$, respectively). Note that attritionmilling was conducted on the D powder and on the oxide solid solutions used as precursors for the CMA2, MD and CMD composite powders. This attrition-milling leads to a contamination of the corresponding powders by some $\mathrm{ZrO}_{2}$ particles, about 1 $\mu \mathrm{m}$ in size.

The powders were uniaxially hot-pressed at 43 $\mathrm{MPa}$ in graphite dies, in a primary vacuum, at $1500^{\circ} \mathrm{C}$ $\left(\mathrm{MgAl}_{2} \mathrm{O}_{4}\right.$ ceramic, $\mathrm{Al}_{2} \mathrm{O}_{3}-$ and $\mathrm{MgAl}_{2} \mathrm{O}_{4}$-matrix composites) or $1600^{\circ} \mathrm{C}(\mathrm{MgO}$ ceramic and $\mathrm{MgO}-$ matrix composites) with a dwell time fixed at $15 \mathrm{~min}$. The dense specimens $(20 \mathrm{~mm}$ in diameter and $2 \mathrm{~mm}$ thick) for mechanical tests were ground with diamond suspensions. Surfaces were polished to an optical finish and thermal and/or chemical etching treatments were adjusted to reveal the grain boundaries.

Starting powders, polished surfaces, etched surfaces and fracture profiles of dense specimens were observed by scanning electron microscopy (SEM). The average grain size of the oxide $\left(G_{\mathrm{m}}\right)$ was determined by the linear intercept method [31]. The maximal size of the metal and $\mathrm{ZrO}_{2}$ particles $\left(d_{\text {metal }}\right.$ and $d_{\mathrm{ZrO} 2}$, respectively) were measured on back-scattered electron images of polished specimens. Relative densities $(d \%)$ were calculated from measurements obtained by the Archimedes method, using the density of graphite $\left(d_{\text {graphite }}=2.25 \mathrm{~g} / \mathrm{cm}^{3}\right)$ for CNTs. The powders and the hot-pressed materials were also studied by X-ray diffraction (XRD).

The transverse fracture strength $\left(\sigma_{\mathrm{f}}\right)$ was determined by the three-point-bending test on parallelepipedic specimens $\left(1.6 \times 1.6 \times 18 \mathrm{~mm}^{3}\right)$ machined with a diamond blade. The fracture toughness $\left(K_{\text {Ic }}\right)$ was measured by the SENB method on similar specimens notched using a diamond blade $0.3 \mathrm{~mm}$ in width. The calibration factor proposed by Brown and Srawley [32] was used to calculate the SENB toughness from the experimental results. Cross-head speed was fixed at $0.1 \mathrm{~mm} / \mathrm{min}$. The values given for $\sigma_{\mathrm{f}}$ and $K_{\mathrm{Ic}}$ are the average of measures on seven and six specimens, respectively. The electrical conductivity of dense specimens was measured at room temperature with d.c. currents on parallelepipedic specimens $\left(1.6 \times 1.6 \times 8 \mathrm{~mm}^{3}\right)$, parallel to their length, i.e. perpendicular to the hot-pressing axis. The current densities used were lower than $160 \mathrm{~mA} / \mathrm{cm}^{2}$.

\section{RESULTS AND DISCUSSION}

\subsection{Powder characterization}

It is first important to note that the metal content has been chosen in order to optimize both the quality of carbon and the quantity of CNTs in the different 

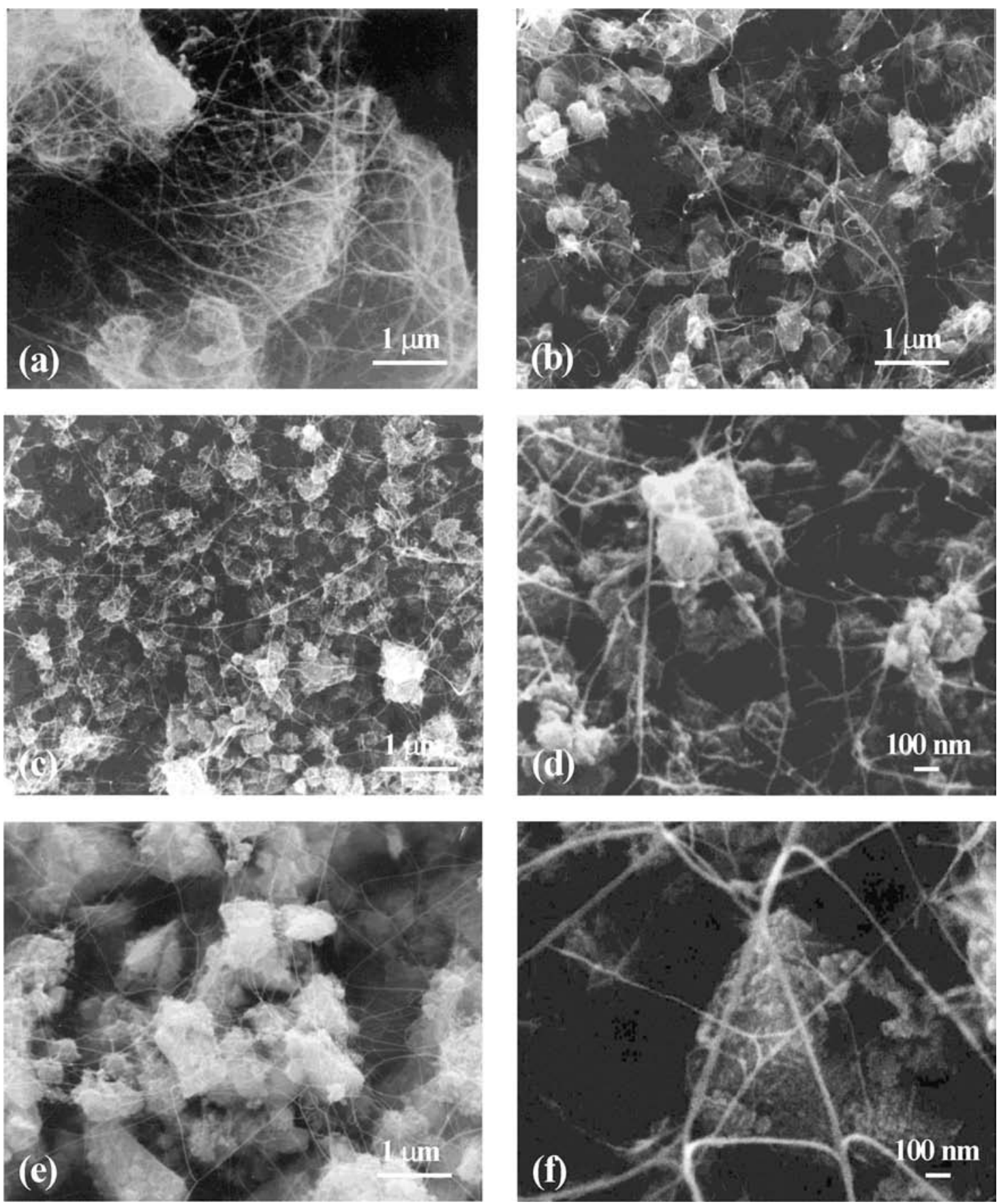

Fig. 1. SEM images of CNT-metal-oxide nanocomposite powders: (a) CNT-Fe- $\mathrm{Al}_{2} \mathrm{O}_{3}$ (CMA1); (b) CNT$\mathrm{Fe}-\mathrm{Al}_{2} \mathrm{O}_{3}$ (CMA2); (c, d) CNT-Co-MgO (CMB); (e, f) CNT-Fe/Co- $\mathrm{MgAl}_{2} \mathrm{O}_{4}$ (CMD).

powders. Thus, depending on the nature of the matrix, a specific metal content was used (Table 1). The XRD patterns (not shown) of the composite powders reveal the peaks of $\alpha$-Fe, $\varepsilon$-Co or cubic-Fe/Co alloy besides those of the involved matrix, $\alpha-\mathrm{Al}_{2} \mathrm{O}_{3}, \mathrm{MgO}$ or $\mathrm{MgAl}_{2} \mathrm{O}_{4}$, respectively. For CMA1 and CMA2, cementite $\mathrm{Fe}_{3} \mathrm{C}$ is also detected. In powders CMA2, $\mathrm{D}, \mathrm{MD}$ and $\mathrm{CMD}$, which derive from attrition-milled oxides, some of the different forms of $\mathrm{ZrO}_{2}$ (cubic, tetragonal and/or monoclinic) are detected, showing some contamination from the $\mathrm{ZrO}_{2}$ balls, which is of the order of a few wt\%.

Macroscopic parameters related to the presence of carbon are reported in Table 1 . The carbon content $\left(C_{n}\right)$ is slightly lower for CMA1 (4.8 wt \%) than for CMA2 (5.7 wt \%), probably owing to the presence of more catalytic particles on the matrix grain surfaces for the latter powder. Indeed, CMA1 and CMA2 powders were prepared from the same oxide solid solution, except that it was attrition-milled prior to 
Table 1. Some characteristics of the metal-oxide and carbon nanotube-metal-oxide nanocomposite powders

\begin{tabular}{|c|c|c|c|c|c|}
\hline Composite & Label & Metal content (wt\%) & $C_{n}(\mathrm{wt} \%)$ & $\Delta S\left(\mathrm{~m}^{2} / \mathrm{g}\right)$ & $\Delta S / C_{n}\left(\mathrm{~m}^{2} / \mathrm{g}\right)$ \\
\hline $\mathrm{CNT}-\mathrm{Fe}-\mathrm{Al}_{2} \mathrm{O}_{3}$ & CMAl & Fe: 8.38 & 4.8 & 13.8 & 288 \\
\hline $\mathrm{CNT}-\mathrm{Fe}-\mathrm{Al}_{2} \mathrm{O}_{3}{ }^{\mathrm{a}}$ & CMA2 & Fe: 8.38 & 5.7 & 15.1 & 265 \\
\hline $\mathrm{Co}-\mathrm{MgO}$ & MB & Co: 13.47 & - & - & - \\
\hline CNT-Co-MgO & CMB & Co: 13.47 & 2.8 & 10.4 & 370 \\
\hline $\mathrm{Fe} / \mathrm{Co}-\mathrm{MgAl}_{2} \mathrm{O}_{4}{ }^{\mathrm{a}}$ & MD & Fe/Co: 9.66 & - & - & - \\
\hline $\mathrm{CNT}-\mathrm{Fe} / \mathrm{Co}-\mathrm{MgAl}_{2} \mathrm{O}_{4}{ }^{\mathrm{a}}$ & CMD & Fe/Co: 9.66 & 4.9 & 10.3 & 210 \\
\hline
\end{tabular}

$C_{n}$ : carbon content; $\Delta S$ : surface area of carbon in $1 \mathrm{~g}$ of composite powder, representing the quantity of nanotubes; $\Delta S / C_{n}$ : specific surface area of carbon, representing the quality of nanotubes.

aSpecimens prepared from powders attrition-milled before reduction. Note that for CNT-containing composites, the carbon content was not taken into account in the calculation of the metal content.

reduction for $\mathrm{CMA} 2$, resulting in a finer agglomerate size. The carbon content for CMD $\left(\mathrm{C}_{\mathrm{n}}=4.9 \mathrm{wt} \%\right)$ is similar to that measured for CMA1, but it is notably lower in the case of CMB $\left(\mathrm{C}_{\mathrm{n}}=2.8 \mathrm{wt} \%\right)$. As proposed elsewhere $[25,26]$, the surface area of carbon found in $1 \mathrm{~g}$ of composite powder $(\Delta S-$ Table 1$)$ is a good representation of the quantity of CNTs in the powder. $\Delta S$ is about 1.5 times higher in $\mathrm{Al}_{2} \mathrm{O}_{3}$-matrix composites than in $\mathrm{MgO}-$ and $\mathrm{MgAl}_{2} \mathrm{O}_{4}-$ matrix composites. From $C_{n}$ and $\Delta S$, one obtains the specific surface area of the carbon $\left(\Delta S / C_{n}\right.$ - Table 1) which represents what we call the quality of carbon in the powder. A higher figure for $\Delta S / C_{n}$ denotes more carbon in the form of CNTs, or CNTs with a smaller diameter and/or less walls, or bundles of CNTs with smaller diameter, i.e. made up of less CNTs [25,26,33]. The CMB powder presents the higher quality of carbon $\left(\Delta S / C_{n}=370 \mathrm{~m}^{2} / g\right)$ whereas the CMD powder presents the lower one $\left(\Delta S / C_{n}=210\right.$ $\left.\mathrm{m}^{2} / \mathrm{g}\right)$.

SEM images of the powders containing CNTs are reported in Fig. 1. The web-like network of CNT bundles is clearly observed for all powders. As mentioned above, the matrix agglomerates are much larger for CMA1 (>10 $\mu \mathrm{m}$ - Fig. 1a) than for CMA2 $(<1 \mu \mathrm{m}-$ Fig. 1b). The matrix agglomerates for CMB (Fig. 1c, d) are only of a few hundreds of nanometers in size. The CNT bundles in this powder are very thin. In the CMD powder (Fig. 1e, f), some matrix agglomerates are almost $2 \mu \mathrm{m}$ in size and the CNT bundles are larger than in CMB (Fig. 1d). These observations are in agreement with the values of $\Delta S / C_{n}$ reported above.

\subsection{Microstructure of the hot-pressed specimens}

Comparing with the XRD patterns recorded on the powders, the XRD patterns of the hot-pressed composites show only a few minor differences. Firstly, dense CMA1 and CMA2 contain more cementite than the corresponding powders. At a high temperature, the larger Fe surface particles probably react with the graphene layers which generally cover them $[16,17,25,29]$ and some CNTs may also react with the Fe particles. This phenomenon is more clearly marked in CMA2 because the powder contains more Fe surface particles owing to the attrition-milling of its precursor oxide powder. Traces of cementite are also detected in CMD. Secondly, in CNT-containing composites, a wide peak corresponding to the distance between graphene layers $\left(\mathrm{d}_{002}=0.34 \mathrm{~nm}\right)$ appears, which reflects a higher crystallization level of the graphenic species than in the powders. Finally, in all dense composites, the width of the metal peaks decreases, compared to the powders, reflecting the growth of the intergranular metal particles upon hotpressing. However, this phenomenon is less marked in CNT-metal-oxide composites, probably because it is inhibited by the presence of graphene layers covering most metal particles in the powders, as well as by the carburization in the case of $\mathrm{Fe}$ particles.

All the CNT-containing composites present unachieved densifications, with relative densities ( $d$ - Table 2) 5-8\% below those of the corresponding carbon-free metal-oxide composites. The $\mathrm{MgO}$ ceramic also presents a fairly poor relative density. Some microstructural characteristics were determined from SEM observations of etched and unetched polished surfaces (Table 2). In the case of $\mathrm{Al}_{2} \mathrm{O}_{3}-$ and $\mathrm{MgAl}_{2} \mathrm{O}_{4}$-matrix composites, the matrix grain size $\left(G_{\mathrm{m}}\right)$ is very small $(0.3-0.8 \mu \mathrm{m})$ and the metal particles size $\left(d_{\text {metal }}\right)$ is not higher than $0.5 \mu \mathrm{m}$. Both $G_{\mathrm{m}}$ and $d_{\text {metal }}$ are higher for $\mathrm{MgO}$-matrix composites (3$7 \mu \mathrm{m}$ and $1.5-2 \mu \mathrm{m}$, respectively). Note that previous works [34] on carbon-free metal-oxide nanocomposites have shown that the metal nanoparticles $(<10$ $\mathrm{nm})$ located within the matrix grains in the powder remain in intragranular position in the dense material and therefore are protected against excessive growth upon hot-pressing. Thus, the metal-oxide and CNTmetal-oxide specimens are hybrid micro/nanocomposites [35] containing both micrometer-sized metal particles which are at intergranular positions and nanometer-sized intragranular metal particles.

The comparison of the matrix grain size for the $\mathrm{MgAl}_{2} \mathrm{O}_{4}$ ceramic $\left(\mathrm{G}_{\mathrm{m}}=13.0 \mu \mathrm{m}\right)$ and for the $\mathrm{MgAl}_{2} \mathrm{O}_{4}-$ matrix composites $\left(\mathrm{G}_{\mathrm{m}}=0.5-0.8 \mu \mathrm{m}\right)$ shows that the matrix grain growth during hot-pressing is hampered by the metal particles (inter- and intragranular) and by the CNTs. Moreover, the specific role of the CNTs in the inhibition of matrix grain growth is confirmed by the average matrix grain size 
Table 2. Relative density and microstructural characteristics of the hot-pressed ceramics and nanocomposites

\begin{tabular}{llcccc}
\hline Ceramic or composite & Label & $d(\%)$ & $G_{\mathrm{m}}(\mu \mathrm{m})$ & $d_{\text {metal }}(\mu \mathrm{m})$ & $d_{\text {Zro2 }}(\mu \mathrm{m})$ \\
\hline $\mathrm{CNT}-\mathrm{Fe}-\mathrm{Al}_{2} \mathrm{O}_{3}{ }^{a}$ & $\mathrm{CMAl}$ & 88.7 & 0.3 & $\leq 0.5$ & - \\
$\mathrm{CNT}-\mathrm{Fe}-\mathrm{Al}_{2} \mathrm{O}_{3}{ }^{a}$ & $\mathrm{CMA} 2$ & 87.5 & 0.3 & $\leq 0.5$ & $\leq 1$ \\
$\mathrm{MgO}$ & $\mathrm{B}$ & 90.1 & 5 & - & - \\
$\mathrm{Co}-\mathrm{MgO}$ & $\mathrm{MB}$ & 96.6 & 7 & $\leq 2$ & - \\
$\mathrm{CNT}-\mathrm{Co}-\mathrm{MgO}$ & $\mathrm{CMB}$ & 92.9 & 3 & $\leq 1.5$ & - \\
$\mathrm{MgAl} \mathrm{O}_{4}{ }^{\mathrm{a}}$ & $\mathrm{D}$ & 99.7 & 13 & - & $\leq 1$ \\
$\mathrm{Fe} / \mathrm{Co}-\mathrm{MgAl}_{2} \mathrm{O}_{4}{ }^{a}$ & $\mathrm{MD}$ & 98.2 & 0.8 & $\leq 0.5$ & $\leq 1$ \\
$\mathrm{CNT}-\mathrm{Fe} / \mathrm{Co}-\mathrm{MgAl}_{2} \mathrm{O}_{4}{ }^{\mathrm{a}}$ & $\mathrm{CMD}$ & 90.6 & 0.5 & $\leq 0.5$ & $\leq 1$ \\
\hline
\end{tabular}

$d$ : relative density calculated by assuming that all carbon has the density of graphite, with $d_{\text {graphite }}=2.25 \mathrm{~g} / \mathrm{cm}^{3} ; G_{\mathrm{m}}$ : average grain size of the oxide; $d_{\text {metal }}$ : diameter of the larger metal particles; $d_{\mathrm{ZrO} 2}$ : diameter of the larger $\mathrm{ZrO}_{2}$ particles in specimens prepared from powders attrition-milled before reduction $\left({ }^{\mathrm{a}}\right)$.

in CMA1 and CMA2 $\left(\mathrm{G}_{\mathrm{m}}=0.3 \mu \mathrm{m}\right)$, which is much smaller than that (ca. $2 \mu \mathrm{m})$ reported for $\mathrm{Fe}-\mathrm{Al}_{2} \mathrm{O}_{3}$ nanocomposites [34]. This is in agreement with our previous results [17, 18]. However, this effect of CNTs is markedly lower in the CMB composites (Table 2), probably because, as will be shown hereafter, most CNTs are destroyed during hot-pressing. Furthermore, SEM observations also reveal that the $\mathrm{ZrO}_{2}$ particles present as a contamination in the CMA2, D, MD and CMD powders are found as slightly submicronic particles in the hot-pressed materials. In addition, it is observed that the CNTcontaining composites present pores which are generally larger than the matrix grains and are sometimes elongated. This is a consequence of the presence of agglomerates in the powders, which are only partially crushed during hot-pressing.

The SEM observations of the fracture surface of CNT-metal-oxide composites (Fig. 2a-d) show the presence of CNT bundles in the materials but in very different quantities from one sample to another. For CMA1 (Fig. 2a), a few long CNT bundles emerge from the fracture surface but most seem to be cut near the surface, perhaps after some pull-out. More very long CNT bundles appear for CMA2 (Fig. 2b), and much more for CMD (Fig. 2d). On the contrary, it is very difficult to observe even a few CNTs on the surface fracture of CMB (A in Fig. 2c). However, some deposits probably composed of carbon are also observed (B in Fig. 2c). Thus, it clearly appears that many CNT bundles remain in CMA1, CMA2 and CMD, whereas most of the CNTs have been destroyed during the hot-pressing of CMB. This could be a consequence either of a specific chemical interaction between the CNTs and the $\mathrm{MgO}$ matrix or of the higher hot-pressing temperature used for the $\mathrm{MgO}$-based specimens $\left(1600^{\circ} \mathrm{C}\right.$ vs $1500^{\circ} \mathrm{C}$ for the other materials), owing to the difficulty in densifying them. A high temperature chemical interaction between the CNTs and the residual gas in the furnace is also a possibility. We also hot-pressed a CNT-Co$\mathrm{MgO}$ composite at a lower temperature $\left(1200^{\circ} \mathrm{C}\right)$. The densification of the material was very low $(82 \%)$ but the quantity of CNT bundles was similar or higher than that observed for CMA2 or CMD (Fig. 2b, d).
The presence of carbon deposits ( $\mathrm{B}$ in Fig. 2c) points towards a thermal instability of CNTs in the primary vacuum at $1600^{\circ} \mathrm{C}$ rather than towards a chemical reaction with $\mathrm{MgO}$.

For $\mathrm{Al}_{2} \mathrm{O}_{3}$ - and $\mathrm{MgAl}_{2} \mathrm{O}_{4}$-matrix materials, a comparison on SEM images of the quantities of CNTs between the powders and dense specimen is difficult, because in the powders many superimposed CNTs appear on a depth of several micrometers (three dimensions), whereas for the hot-pressed specimen, only the CNTs at the fracture surface are observed (two dimensions). This can lead to an underestimation of the CNTs quantity in the latter case. However, it seems that the quantity of CNTs is significantly decreased during the hot-pressing, particularly for $\mathrm{Al}_{2} \mathrm{O}_{3}$-based composites.

\subsection{Electrical conductivity}

The electrical conductivity $(\sigma-$ Table 3$)$ of all CNT-containing composites is in the range 0.2-4.0 $\mathrm{S} \mathrm{cm}{ }^{-1}$ whereas the ceramics and the metal-ceramic composites are insulating $\left(\sigma<10^{-9} \mathrm{~S} \mathrm{~cm}^{-1}\right)$. Moreover, from one specimen to another, the values are fairly well correlated to the quantity of CNTs observed on the fracture surfaces (Fig. 2a-d). Indeed, the lower value is obtained for CMB in which the majority of CNTs seems to have been destroyed (Fig. 2c). Both CMA2 and CMD composites have been prepared from very fine powders, thus leading to a better dispersion of the CNT bundles within the matrix (Fig. 1b, c) compared to CMA1 for which the matrix agglomerates are much larger. This probably leads to a better connectivity of the CNTs in CMA2 and CMD dense composites than in CMA1, accounting for the higher electrical conductivity of the former materials (1.5-4.0 vs $0.4-0.8 \mathrm{~S} \mathrm{~cm}^{-1}$ ). Furthermore, the values are significantly higher for CMA2 than for CMD because the quantity parameter $(\Delta S-$ Table 1) is $50 \%$ higher for CMA2 than for CMD.

To assess the real role of the CNTs in the electrical conductivity of $\mathrm{CMB}$, the $\mathrm{MgO}$ matrix was dissolved by a mild $\mathrm{HCl}$ treatment known to not damage the CNTs [30] and the so-obtained carbon species were observed by high resolution electron microscopy. In agreement with SEM observations (Fig. 2c), only a 

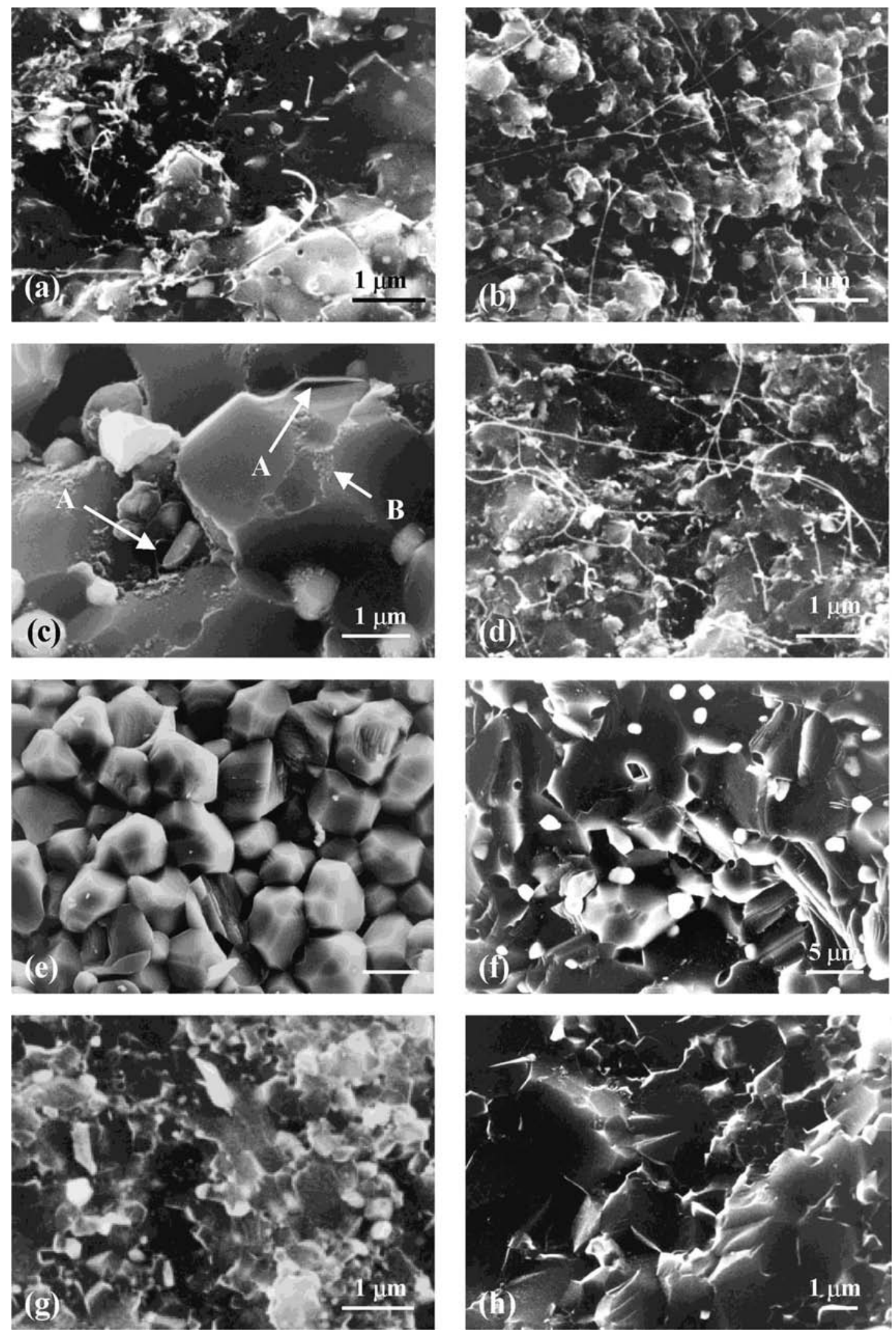

Fig. 2. SEM images of the fracture surface of ceramics and nanocomposites: (a) CNT-Fe- $\mathrm{Al}_{2} \mathrm{O}_{3}(\mathrm{CMA1})$; (b) CNT-Fe- $\mathrm{Al}_{2} \mathrm{O}_{3}$ (CMA2); (c) CNT-Co-MgO (CMB); (d) CNT-Fe/Co- $\mathrm{MgAl}_{2} \mathrm{O}_{4}$ (CMD); (e) $\mathrm{MgO}$ (B); (f) $\mathrm{Co}-\mathrm{MgO}$ (MB); (g) $\mathrm{MgAl}_{2} \mathrm{O}_{4}$ (D); (h) $\mathrm{Fe} / \mathrm{Co}-\mathrm{MgAl}_{2} \mathrm{O}_{4}$ (MD). 


\begin{tabular}{|c|c|c|c|c|c|}
\hline Ceramic or composite & Label or reference & $\sigma\left(\mathrm{S} \mathrm{cm}^{-1}\right)$ & $\sigma_{\mathrm{f}}(\mathrm{MPa})$ & $K_{\mathrm{Ic}}\left(\mathrm{MPa} \mathrm{m}{ }^{1 / 2}\right)$ & Fracture mode \\
\hline $\mathrm{Al}_{2} \mathrm{O}_{3}$ & {$[34]$} & - & 335 & 4.4 & Intergranular \\
\hline $\mathrm{Fe}-\mathrm{Al}_{2} \mathrm{O}_{3}$ & [34] & - & 630 & 7.2 & Mixed \\
\hline $\mathrm{CNT}-\mathrm{Fe}-\mathrm{Al}_{2} \mathrm{O}_{3}$ & [17] & - & 540 & 3.6 & Mixed \\
\hline $\mathrm{CNT}-\mathrm{Fe}-\mathrm{Al}_{2} \mathrm{O}_{3} *$ & [18] & - & 295 & 2.7 & Intergranular \\
\hline $\mathrm{CNT}-\mathrm{Fe}-\mathrm{Al}_{2} \mathrm{O}_{3}$ & CMAl & $0.4-0.8$ & 400 & 5.0 & Mixed \\
\hline $\mathrm{CNT}-\mathrm{Fe}-\mathrm{Al}_{2} \mathrm{O}_{3} *$ & CMA2 & $2.8-4.0$ & 296 & 3.1 & Intergranular \\
\hline $\mathrm{MgO}$ & B & n.m & 202 & - & Intergranular \\
\hline $\mathrm{Co}-\mathrm{MgO}$ & MB & n.m. & 283 & - & Mixed \\
\hline $\mathrm{CNT}-\mathrm{Co}-\mathrm{MgO}$ & CMB & 0.2 & 254 & - & Intergranular \\
\hline $\mathrm{MgAl}_{2} \mathrm{O}_{4} *$ & $\mathrm{D}$ & n.m. & 308 & - & Transgranular \\
\hline $\mathrm{Fe} / \mathrm{Co}-\mathrm{MgAl}_{2} \mathrm{O}_{4} *$ & MD & n.m. & 212 & 2.94 & Mixed \\
\hline $\mathrm{CNT}-\mathrm{Fe} / \mathrm{Co}-\mathrm{MgAl}_{2} \mathrm{O}_{4} *$ & CMD & $1.5-1.8$ & 221 & 1.71 & Mixed \\
\hline
\end{tabular}

${ }^{a}$ Specimens prepared from powders attrition-milled before reduction; n.m.: not measurable; mixed: the fracture presents both the inter- and transgranular characters.

small proportion of undamaged CNTs were observed, the majority of carbon being found in the form of disorganized graphene layers, which probably reflects a damage to the CNTs during hot-pressing at $1600^{\circ} \mathrm{C}$. Moreover, similar experiments have been conducted on a composite hot-pressed at $1700^{\circ} \mathrm{C}$ and have revealed the transformation of all the CNTs into disorganized graphene layers. This material had a very low electrical conductivity $\left(\sigma<10^{-8} \mathrm{~S} \mathrm{~cm}^{-1}\right)$. These results show that, for the three categories of $\mathrm{CNT}-$ metal-oxide composites, including CMB in which the quantity of CNTs seems to be very low, the electrical conductivity can be attributed to a percolation phenomenon between CNT bundles. The very high aspect ratio of the CNT bundles $\left(>10^{4}\right)$ makes the percolation possible with a very small content of CNTs. Similarly, Sandler et al. reported, for MWNTs-polymer composites, an electrical conductivity equal to $10^{-2} \mathrm{~S} \mathrm{~cm}^{-1}$ with only $0.1 \mathrm{vol} \%$ of MWNTs [3] and Yoshino et al. measured $0.05-0.30 \mathrm{~S} \mathrm{~cm}^{-1}$ with 10 and 20 vol\% of MWNTs, respectively [7]. We have estimated that in the present starting powders, the CNTs volume fraction could be up to about 20 vol\% but it seems to be much lower in the dense materials (perhaps only a few vol\% and even less in CMB), owing to damages during hot-pressing. In the present experiments, most CNTs have only one or two walls and are less than $6 \mathrm{~nm}$ in diameter, which is favorable to an enhanced conductivity, at identical volume fractions, in comparison with large MWNTs. Thus, we infer that the difference in the characteristics of the CNTs explains why we obtain a higher electrical conductivity than previously reported [3, 7]. Some differences in the CNTs structure and the resulting electrical behavior (metallic or semiconductor) could also account for these differences.

\subsection{Mechanical properties and fracture surface characteristics}

Compared to previously studied $\mathrm{CNT}-\mathrm{Fe}-\mathrm{Al}_{2} \mathrm{O}_{3}$ composites [17, 18], CMA1 and CMA2 differ both by a higher quantity of CNTs in the starting powder and a better quality of carbon (much less nanofibers).
The characteristics of CMA1 (Table 3) can be compared with those of the composite reported in Ref. [17], both having been prepared from powders with micrometer-sized agglomerates: the fracture strength of CMA1 is lower but its fracture toughness is higher, which could be correlated to some differences in the microstructure, the densification is lower for CMA1 $(88.7 \%$ vs $91 \%)$ and the matrix grains are smaller $(0.3$ vs about $1 \mu \mathrm{m})$. The higher quantity of CNTs in CMA1 seems to favor the inhibition of matrix grain growth and to hamper the densification. Consequently, more elongated pores subsist in the present composite, which could explain the lower value of $\sigma_{\mathrm{f}}$ (Table 3). On the contrary, the increase in the quantity of CNTs in CMA1 may result in an easier transfer of the stress and thus could account for the significant increase in the fracture toughness (from 3.6 $\mathrm{MPa} \mathrm{m}^{1 / 2}$ for [17] to $5.0 \mathrm{MPa} \mathrm{m}^{1 / 2}$ for CMA1).

It has been shown $[34,35]$ that the hybridization of microcomposites and nanocomposites could result in a further improvement in both the fracture strength and fracture toughness, which was associated with a mixed inter/trans-granular fracture mode. The fracture strength and fracture toughness of CMA1 are higher than those of the $\mathrm{Al}_{2} \mathrm{O}_{3}$ ceramic prepared by the same route [34], but are lower than those of $\mathrm{Fe}-\mathrm{Al}_{2} \mathrm{O}_{3}$ composites [34]. Taking into account that CMA1 is poorly densified (only $88.7 \%$ vs about $98 \%$ [34]), the mechanical properties can be considered as not so poor and a possible contribution of the CNTs to the reinforcement is not to be ruled out. However, it is not clearly demonstrated.

The characteristics of CMA2 (Table 3) are comparable to those of the composite reported in Ref. [18], both having been prepared from powders derived from attrition-milled oxide precursors. Compared to CMA1 and the composite in Ref. [17], it appears that the attrition-milling is detrimental to $\sigma_{\mathrm{f}}$ and $K_{\mathrm{Ic}}$ in the resulting composites (Table 3 ). Firstly, less intragranular Fe particles are obtained upon reduction in the composite powders because the oxide agglomerates in the precursor powders are submicronic, and thus their proportion is also lower in the dense specimens. 
In these nanocomposites, the intragranular nanoparticles generally induce the transgranular fracture mode, which contributes to the mechanical reinforcement [34]. In contrast, for CMA2 and for the composite in Ref. [18], the fracture mode is intergranular probably in part because there are too few intragranular Fe nanoparticles. Secondly, in the CMA2 powder the CNT bundles are more intimately dispersed in the matrix than in CMA1 and in the dense CMA2 specimen, the pores are smaller, less elongated but more numerous than in CMA1. Consequently, it is observed that in CMA2 (Fig. 2b), more CNT bundles are located into the pores and are thus not constrained and damaged during the fracture. In contrast, a higher proportion of CNT bundles are included in the dense parts of CMA1 and SEM observations (Fig. 2a) reveal that these CNTs have been damaged during the fracture. Thus if CNTs could contribute to any reinforcement in this kind of nanocomposite, they would be efficient only in CMA1. Moreover, the presence in CMA2 of a small quantity of micrometric $\mathrm{ZrO}_{2}$ particles, which usually reinforce the material, cannot explain the low values of $\sigma_{\mathrm{f}}$ and $K_{\mathrm{Ic}}$ for CMA2.

Despite an uncompleted densification $(90.1 \%)$, the fracture strength measured for the $\mathrm{MgO}$ ceramic $\left(\sigma_{\mathrm{f}}=202 \mathrm{MPa}-\right.$ Table 3$)$ is comparable to the values reported by Rice et al. [36] for non-annealed hotpressed $\mathrm{MgO}$ with a similar average grain size (5 $\mu \mathrm{m})$. The comparison with $\mathrm{MgO}-$ matrix nanocomposites shows an evolution of $\sigma_{\mathrm{f}}$ similar to that between $\mathrm{Al}_{2} \mathrm{O}_{3}$ and the $\mathrm{Al}_{2} \mathrm{O}_{3}$-matrix composites (Table 3). Indeed, $\sigma_{\mathrm{f}}$ is higher for $\mathrm{Co}-\mathrm{MgO}(\mathrm{MB})$ than for $\mathrm{MgO}$ (B) but slightly lower for CNT-Co-MgO (CMB) than for $\mathrm{MB}$. Comparing $\mathrm{B}$ and $\mathrm{MB}$, the improvement of the densification $(96.6 \%$ vs $90.1 \%$ - Table 2) may be sufficient to explain the increase in $\sigma_{\mathrm{f}}$, but it is also associated with a transition of the fracture mode from purely intergranular to mixed inter/transgranular (Fig. 2e, f). This may be provoked by the presence of intragranular metal nanoparticles, as in the $\mathrm{Al}_{2} \mathrm{O}_{3}-$ matrix nanocomposites [34]. The lower value of $\sigma_{\mathrm{f}}$ for $\mathrm{CMB}$, compared to $\mathrm{MB}$, associated with the transition to a fully intergranular fracture mode, could be correlated with its lower densification but it may also result from the presence of the disordered graphene sheets derived from damaged CNTs. The possible contribution of non-damaged CNTs to the mechanical properties of these $\mathrm{MgO}-$ matrix nanocomposites are to be ruled out.

The fracture strength equal to $308 \mathrm{MPa}$ obtained for the $\mathrm{MgAl}_{2} \mathrm{O}_{4}$ ceramic (D) is higher than the values previously reported by other authors [37, 38], probably as a consequence of the high densification of the present specimen $(99.7 \%)$ but also possibly owing to a beneficial effect of the micrometric tetragonal $\mathrm{ZrO}_{2}$ particles [39], a contamination which occurred during the attrition-milling of the starting oxide powder. The fracture mode in D is clearly transgranular (Fig. 2g) showing that for the present material, the critical grain size related to the change of fracture mode is below
$13 \mu \mathrm{m}$ (Table 2). Both $\mathrm{MgAl}_{2} \mathrm{O}_{4}$-matrix composites (MD and CMD) have a lower fracture strength than the ceramic D (Table 3) despite a great refinement of the matrix grain size $\left(G_{\mathrm{m}}-\right.$ Table 2$)$. However, their fracture mode remains partially transgranular (Fig. $2 \mathrm{~d}, \mathrm{~h}$ ) owing to the metal nanoparticles, a strong proportion of which are included inside the matrix grain in these nanocomposites as reported by Quénard et al. [40]. The CMD composite, which is very incompletely densified (90.6\%), shows a fracture strength similar to that of MD but presents a much lower fracture toughness. Indeed, many CNTs appear on the fracture surface of CMD (Fig. 2d) but most emerge from pores, as in CMA1 (Fig. 2b) and do not seem to have been constrained during the fracture. Only a few CNTs, included in the densified parts of the material, have been cut near the fracture surface. Thus, we infer that in CMD, as in CMA2, most CNTs cannot be efficient for an eventual reinforcement of the material.

Some observations of the fracture surface of the CMA1 composite were conducted at a higher magnification using a field-emission gun scanning electron microscope (SEM-FEG - Fig. 3). Some CNT bundles have been stretched upon hot-pressing, acquiring the shape of the matrix grains at the grain boundary (Fig. 3a). Other CNTs have left their impression at the surface of the matrix grains (Fig. 3b) showing that some wetting of the CNTs by the matrix occurs at the grain boundary during hotpressing. In a previous paper [17], it was shown that some CNTs embedded in the matrix grain were cut after some pull-out. The same effect also seems to occur with CNT bundles located at matrix grain boundaries in the present composites (Fig. 3c, d). Moreover, small holes can be observed (h in Fig. 3c), which may have been the location of CNTs extracted from a grain. It is well known that, in any fiberreinforced composite, one of the keys to an efficient reinforcement is that the fiber-matrix interface is not too weak but also not too strong [41], thus allowing some energy absorption under stress by the decohesion of these interfaces which often leads to the fiber pull-out.

The SEM observations show: (i) that pull-out phenomena occur in $\mathrm{CNT}-\mathrm{Fe}-\mathrm{Al}_{2} \mathrm{O}_{3}$ composites; (ii) that $\mathrm{CNT}$ bundles may be wetted by the matrix at the grain boundaries; or (iii) have been included inside the matrix grains during hot-pressing. These microscopic observations show that some of the CNT bundles, probably weakly bonded to $\mathrm{Al}_{2} \mathrm{O}_{3}$, could act to reinforce the ceramic. However, some CNTs are located in the pores and therefore cannot contribute to the reinforcement of the material. Another important point for achieving a reinforcement is to have a sufficient volume fraction of tubular carbon. This parameter seems to be rather high in the powders: it has been previously estimated to be of the order of 20 vol\% [18] and could be higher in the present $\mathrm{CNT}-\mathrm{Fe}-\mathrm{Al}_{2} \mathrm{O}_{3}$ powders. However, on SEM 

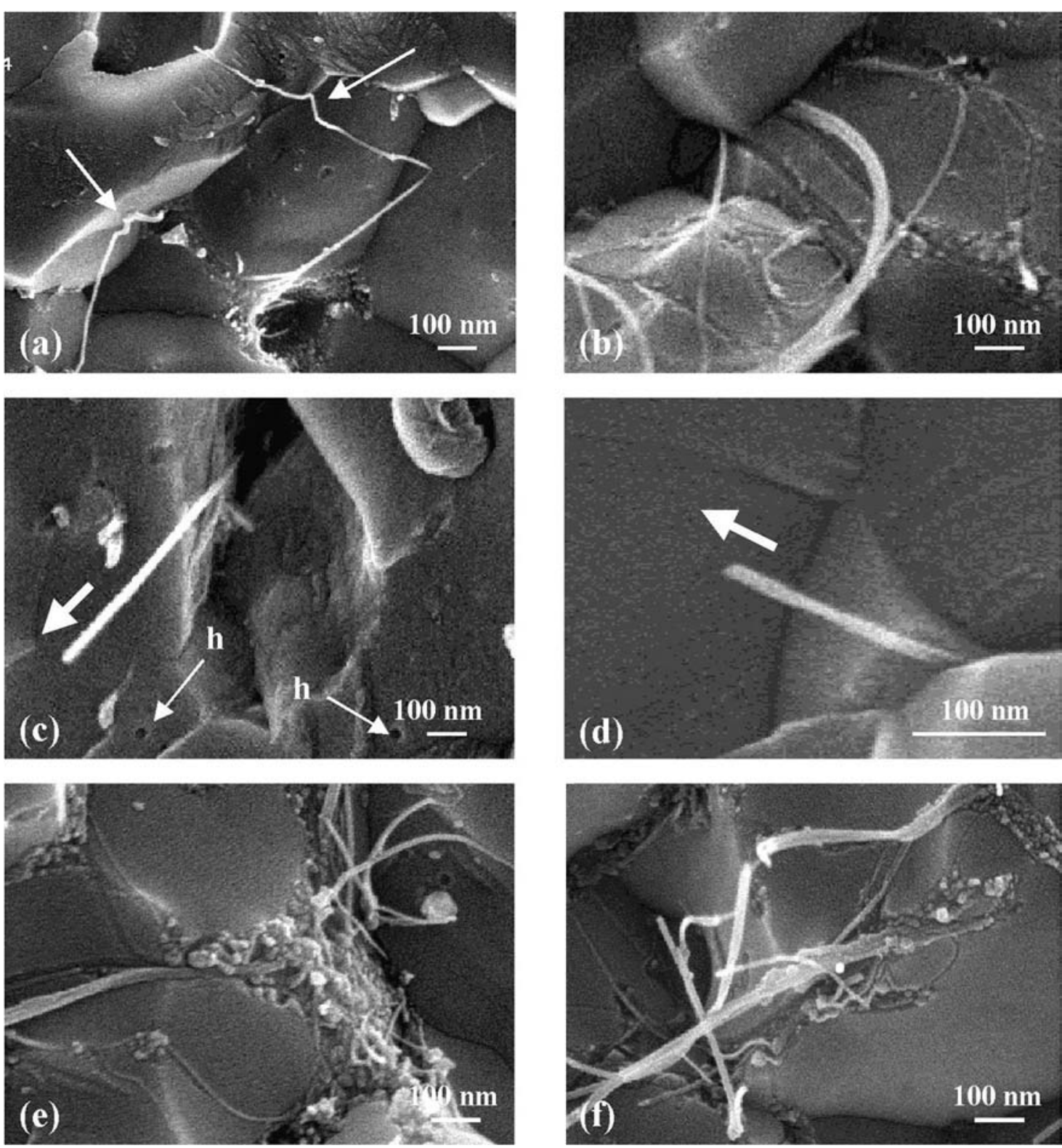

Fig. 3. SEM-FEG images of the fracture of the CNT-Fe- $\mathrm{Al}_{2} \mathrm{O}_{3}$ (CMA1) composite showing some aspects of the CNT-matrix interactions.

images of the dense composites (Fig. 2a-d), the volume fractions seem to be much lower and SEM-FEG images furthermore show a lot of carbon deposits at the matrix grain junctions (Fig. 3e, f) arising from the damage of CNTs upon hot-pressing, producing disordered graphene sheets which gather at grain junctions.

\section{CONCLUSIONS}

$\mathrm{CNT}-\mathrm{Fe}-\mathrm{Al}_{2} \mathrm{O}_{3}$ composites have been prepared by hot-pressing composite powders where the quantity of CNTs has greatly been increased in comparison with previous works. Novel dense CNT-Co-MgO and $\mathrm{CNT}-\mathrm{FeCo}-\mathrm{MgAl}_{2} \mathrm{O}_{4}$ composites have also been prepared. The CNTs, mainly single or double-walled, have grown in situ in the starting powders and thus are very homogeneously dispersed between the metal-oxide grains.

With the $\mathrm{Al}_{2} \mathrm{O}_{3}$ matrix, the increase of the quantity of CNTs in the powder leads to a refinement of the microstructure of the hot-pressed specimen but without a significant gain in the volume fraction of CNTs. With both the $\mathrm{Al}_{2} \mathrm{O}_{3}$ and the $\mathrm{MgAl}_{2} \mathrm{O}_{4}$ matrix, a fraction of the CNTs seems to be destroyed during the hot-pressing at $1500^{\circ} \mathrm{C}$. When using the $\mathrm{MgO}$ matrix, most CNTs are destroyed during a hot-pressing at $1600^{\circ} \mathrm{C}$, but the CNTs are not damaged if the treatment is limited to $1200^{\circ} \mathrm{C}$. It seems that the quantity of CNTs retained in the massive composite is more 
dependant of the treatment temperature than of the nature of the oxide matrix. CNT damaging produces disordered graphene layers which gather at matrix grain junctions.

Probably owing to a too-low relative density (87$93 \%$ ), the fracture strength and the fracture toughness of the CNT-containing composites are generally lower than those of the carbon-free metal-oxide composites and only marginally higher than those of the ceramics. Microscopical observations show that some CNTs are trapped inside the matrix grains or at grain boundaries and seem to be wetted by the matrix in the case of alumina. Most of these CNTs are cut near the fracture surface after some pull-out and could contribute to a mechanical reinforcement. However, this is not demonstrated at a macroscopic scale. It is necessary in future works to improve the preparation process to obtain composites with a higher densification and including a higher volume fraction of CNTs.

Whereas the ceramics and metal-oxide nanocomposites are insulators, the carbon nanotube-metaloxide composites are electrical conductors with an electrical conductivity in the range $0.2-4.0 \mathrm{~S} \mathrm{~cm}^{-1}$ owing to the percolation of the CNTs. The values of the electrical conductivity are fairly well correlated to the relative quantity of CNTs, the specimens becoming insulators when the CNTs are destroyed. The soproduced disordered graphene layers do not percolate. For the first time, it has been shown that CNTs confer an electrical conductivity to ceramic-matrix composites, which retain the mechanical properties of the ceramic.

Acknowledgements-The authors would like to thank Mr L. Datas for his assistance in the HREM observations, which have been performed at the Service Commun de Microscopie Electronique à Transmission, Université Paul-Sabatier.

\section{REFERENCES}

1. Ajayan, P. M., Stephan, O., Colliex, C. and Trauth, D., Science, 1994, 265, 1212.

2. Shadler, L. S., Giannaris, S. C. and Ajayan, P. M., Appl. Phys. Lett., 1998, 73, 3842.

3. Yoshino, K., Kajii, H., Araki, H., Sonoda, T., Take, H. and Lee, S., Full. Sci. Technol., 1999, 7, 695.

4. Musa, I., Baxendale, M., Amaratunga, G. A. J. and Eccleston, W., Synth. Met., 1999, 102, 1250.

5. Curran, S., Davey, A. P., Coleman, J., Dalton, A., McCarthy, B., Maier, S., Drury, A., Gray, D., Brennan, M. Ryder, K., Lamy de la Chapelle, M., Journet, C., Bernier, P., Byrne, H. J., Caroll, D., Ajayan, P. M., Lefrant, S. and Blau, W., Synth. Met., 1999, 103, 2559.

6. Bower, C., Rosen, R., Jin, L., Han, J. and Zhou, O., Appl. Phys. Lett., 1999, 74, 3317.

7. Sandler, J., Shaffer, M. S. P., Prasse, T., Bauhofer, W., Schulte, K. and Windle, A. H., Polymer, 1999, 40, 5967.

8. Lourie, O., Wagner, H. D. and Levin, N., Polymer, 1997, 38, 5699.

9. Wagner, H. D., Lourie, O., Feldman, Y. and Tenne, R., Appl. Phys. Lett., 1998, 72, 188.
10. Lourie, O. and Wagner, H. D., Appl. Phys. Lett., 1998, 72, 188.

11. Lourie, O. and Wagner, H. D., Composites Sci. Technol., 1999, 59, 975.

12. Files, B. S., Proceedings of the International Conference on Integrated Nano/Microtechnology for Space Applications, 1-6 November. Johnson Space Center Houston, TX, 1998.

13. Kuzumaki, T., Miyazawa, K., Ichinose, H. and Ito, K., J. Mater. Res., 1998, 13, 2445.

14. Xu, C. L., Wei, B. Q., Ma, R. Z., Liang, J., Ma, X. K. and Wu, D. H., Carbon, 1999, 37, 855.

15. Ma, R. Z., Wu, J., Wei, B. Q., Liang, J. and Wu, D. H., J. Mater. Sci., 1998, 33, 5243.

16. Peigney, A., Laurent, Ch., Dumortier, O. and Rousset, A., J. Eur. Ceram. Soc., 1998, 18, 1995.

17. Laurent, Ch., Peigney, A., Dumortier, O. and Rousset, A., J. Eur. Ceram. Soc., 1998, 18, 2005.

18. Peigney, A., Laurent, Ch., Flahaut, E. and Rousset, A., Ceram. Int., 2000, 26, 677.

19. Treacy, M. M. J., Ebbesen, T. W. and Gibson, J. M., Nature, 1996, 381, 678.

20. Ruoff, R. S. and Lorents, D. C., Carbon, 1995, 33, 925.

21. Salvetat, J. P., Briggs, G. A. D., Bonard, J. M., Bacsa, R. R., Kulik, A. J., Stockli, T., Burnham, N. A. and Forro, L., Phys. Rev. Lett., 1999, 82, 944.

22. Dai, H., Wong, E. W. and Lieber, C. M., Science, 1996, 272, 523.

23. Ebbesen, T. W., Lezec, H. J., Hiura, H., Benett, J. W., Ghaemi, H. F. and Thio, T., Nature, 1996, 382, 54.

24. Peigney, A., Laurent, Ch., Dobigeon, F. and Rousset, A., J. Mater. Res., 1997, 12, 613.

25. Peigney, A., Laurent, Ch. and Rousset, A., J. Mater. Chem., 1999, 9, 1167.

26. Laurent, Ch., Peigney, A., Flahaut, E. and Rousset, A., Mater. Res. Bull., 2000, 35(5), in press.

27. Govindaraj, A., Flahaut, E., Laurent, Ch., Peigney, A., Rousset, A. and Rao, C. N. R., J. Mater. Res., 1999, 14, 2567.

28. Flahaut, E., Govindaraj, A., Peigney, A., Laurent, Ch., Rousset, A. and Rao, C. N. R., Chem. Phys. Lett., 1999, 300, 236.

29. Coquay, P., De Grave, E., Vandenberghe, R.E., Dauwe, C., Flahaut, E., Laurent, Ch., Peigney, A. and Rousset, A., Acta Mater., 2000, 48, 3015.

30. Flahaut, E., Peigney, A., Laurent, Ch. and Rousset, A., J. Mater. Chem., 2000, 10, 249.

31. Mendelsohn, M. I., J. Am. Ceram. Soc., 1969, 52, 443.

32. Brown, W. F. and Srawley, J. E., Plane Strain Crack Toughness Testing of High Strength Metallic Materials, ASTM Spec. Tech. Pub., 410. ASTM, Philadelphia, PA, 1966.

33. Peigney, A., Laurent, Ch., Flahaut, E. and Rousset, A., Carbon, 2000, accepted for publication.

34. Devaux, X., Laurent, Ch., Brieu, M. and Rousset, A., in Composite Materials, eds A. T. Di Benedetto, L. Nicolais and R. Watanabe. Elsevier Science Publishers BV, Amsterdam, 1992, p. 209.

35. Niihara, K., J. Ceram. Soc. Jpn., 1991, 99, 974.

36. Rice, R. W., Br. Ceram. Soc. Proc., 1972, 20, 329.

37. Baudin, C., Martinez, R. and Pena, P., J. Am. Ceram. Soc., 1995, 78, 1857.

38. Fujita, M., Yoshimatsu, H., Osaka, A. and Miura, Y., J. Ceram. Soc. Jpn. Int. Ed., 1994, 103, 81.

39. Quénard, O., Peigney, A., Laurent, Ch. and Rousset, A., Mater. Res. Bull., 2000, 35, in press.

40. Quénard, O., Laurent, Ch., Peigney, A. and Rousset, A., Key Engng Mater., 1997, 132-136, 944.

41. Després, J. -F. and Monthioux, M., J. Eur. Ceram. Soc., 1995, 15, 209. 